\title{
COMO NÃO ESQUECER DE VIVER O PRESENTE: UM ENSAIO SOBRE A ESPIRITUALIDADE DO AMOR
}

\author{
Cassiana Lopes Stephan 1 \\ Universidade Federal do Paraná (UFPR) \\ (D) https://orcid.org/0000-0003-2687-1202 \\ E-mail: cassianastephan@yahoo.com.br
}

\section{RESUMO:}

Pierre Hadot nos mostra, em suas interpretações sobre Goethe e a tradição dos exercícios espirituais, que o amor verdadeiro possui um potencial transformador, pois corresponde a um exercício do espírito capaz de desvelar o ideal que envolve e constitui a realidade dos amantes. Diferentemente, Foucault explica, através de Baudelaire e da cultura da estética da existência, que a experiência transfiguradora do amor propicia a criação do tempo presente como que por ficção e não pela presença do ideal no real. A partir disso, talvez possamos afirmar que a espiritualidade do amor, concebida por Hadot, residiria na eternização do instante presente e na universalização da alma, cuja beleza articula os amantes idealmente à Natureza. Por outro lado, no caso da estética da existência foucaultiana a espiritualidade do amor concerniria à violação ficcional da condição que ata o si, os outros e o mundo à saudade do passado ou à ansiedade pelo futuro. Sendo assim, neste ensaio vislumbramos (a) pontuar as diferenças entre Hadot e Foucault no que concerne à vivência do tempo presente e à espiritualidade do amor para (b) indicarmos de que modo ambos compreenderiam a movimentação histórica do si e dos outros no mundo.

PALAVRAS-CHAVE: Espiritualidade; Amor; Beleza; Ideal; Ficção.

\section{HOW TO NOT FORGET TO LIVE THE PRESENT: AN ESSAY ON THE SPIRITUALITY OF LOVE}

\begin{abstract}
:
Pierre Hadot shows us, in his interpretations of Goethe and the tradition of spiritual exercises, that true love has a transforming potential, since it corresponds to an exercise of the spirit capable of revealing the ideal that surrounds and constitutes the reality of lovers. Differently, Foucault explains, by Baudelaire and the culture of the aesthetics of existence, that the transfiguring practice of love propitiates the creation of the present time as if through fiction and not by the presence of the ideal in the real. Therefore, perhaps we can affirm that the spirituality of love, conceived by Hadot, would reside in the eternalization of the present moment and in the universalization of the soul, whose beauty articulates the lovers ideally to the Nature. On the other hand, in the case of the foucauldian aesthetics of existence, the spirituality of love would concern the fictional violation of the condition that binds the self, the others and the world to the nostalgia for the past or to the anxiety for the future. Thus, in this essay we envisage (a) to point out the differences between Hadot and Foucault regarding the experience of the present time and the spirituality of love in order to (b) indicate how both would understand the historical movement of the self and the others in the world.
\end{abstract}

KEYWORDS: Spirituality; Love; Beauty; Ideal; Fiction.

\footnotetext{
${ }^{1}$ Doutoranda em Filosofia na Universidade Federal do Paraná (UFPR), Curitiba - PR, Brasil. Bolsista/CAPES.

STEPHAN. Cassiana Lopes. Como não esquecer de viver o presente: um ensaio sobre a espiritualidade do amor. Griot : Revista de Filosofia, Amargosa - BA, v.18, n.2, p.375-396, dezembro, 2018. 


\section{Para reintroduzir a lembrança do tempo presente}

A relação do si mesmo com o tempo presente se delineia como um problema ético-político tanto para Pierre Hadot quanto para Michel Foucault. Ambos retornam ao passado filosófico do estoicismo e, respectivamente, ao passado das literaturas de Goethe e Baudelaire para nos relembrar os motivos pelos quais o preceito moral que predica viver o presente ainda se faz urgente. Para Pierre Hadot e para Michel Foucault, a vida que tenta viver o presente corresponde à vida que faz a experiência da espiritualidade do amor, isto é, corresponde à existência que deseja e age em virtude da sua própria transformação ética e de sua intervenção política no mundo. A espiritualidade do amor parece residir, seja no âmbito da tradição dos exercícios espirituais hadotianos ou no da cultura da estética da existência foucaultiana, no caráter transfigurador das práticas afetivas, as quais ao mesmo tempo constituem e são constituídas pela preparação ascensional ou ascética que habilita o acesso do si à verdade. (HADOT, 2008, p.57; FOUCAULT, 2010, p. 16) O amor confina com a espiritualidade na medida em que possui uma dimensão éticopolítica que nos insere no presente, como explica Hadot, ou na medida que nos proporciona a sua criação, como nos mostra Foucault. Mais precisamente, no caso de P. Hadot a espiritualidade do amor se atrela à experiência excepcional do presente, que oferece aos amantes a possibilidade de suas próprias modificações, através da identificação com o Todo e da subsequente conformidade ao Destino. (HADOT, 2008, p.82) Diferentemente, M. Foucault parece nos propor que a espiritualidade do amor não decorre desta experimentação excepcional do presente, mas antes impele à sua fabricação como que por ficção. (FOUCAULT, 2015, p.48) Sendo assim, no decorrer de nosso ensaio gostaríamos de elaborar a relação entre os vínculos sociais e a experiência de viver o presente no que concerne à transformação ética do si mesmo e à sua intervenção política no mundo. Por um lado, iremos nos apoiar nas interpretações de Hadot acerca das continuidades entre o estoicismo e Goethe no que tange à tradição dos exercícios espirituais; por outro lado, sob a clave da estética da existência foucaultiana, nos debruçaremos sobre as possíveis conexões entre o cuidado de si estoico e o dandismo de Baudelaire.

Os supracitados entrecruzamentos teórico-práticos entre filosofia e literatura, respaldados pelos exercícios espirituais e pela estética da existência, conduzem-nos a duas respostas distintas à pergunta que manifesta a premência da relação do si com o tempo presente. Estas duas respostas decorrem das diferenças entre Hadot e Foucault no que diz respeito ao estatuto filosófico do presente e dos vínculos afetivos relativamente à arte de viver. A nossa hipótese é a de que a excepcionalidade do tempo presente em Hadot se definiria pelo caráter utópico da espiritualidade do amor, que desloca o si e o outro à eternidade do tempo e à totalidade do espaço, pois $o$ instante que circunscreve o êxtase fusional dos amantes, representado por Fausto e Helena, é "símbolo do Ser, se nos recordamos que Goethe definiu o símbolo como a "revelação, viva, no instante, do inexplorável." (HADOT, 2008, p.82, tradução nossa) Em contraposição, supomos que a ficcionalidade do tempo presente em Foucault se atrelaria ao aporte crítico da espiritualidade do amor, a qual insere os

STEPHAN. Cassiana Lopes. Como não esquecer de viver o presente: um ensaio sobre a espiritualidade do amor. Griot : Revista de Filosofia, Amargosa - BA, v.18, n.2, p.375-396, dezembro, 2018. 
laços afetivos no quadro da "arte da inservidão voluntária, aquela da indocilidade refletida." (FOUCAULT, 2015, p.39, tradução nossa) A arte da crítica subsidiaria o êxtase atinente à comunicação que simultaneamente aproxima e distancia os amantes, de modo a movê-los para fora daquela utopia que tenta apagar a finitude e a incompletude do si mesmo, por meio da idealização do que se apresenta como trivial. Segundo Foucault, “(...) fazer amor é sentir o corpo refluir sobre si, é existir, enfim, fora de toda utopia, com toda densidade, entre as mãos do outro." (FOUCAULT, 2013, p. 16)

Talvez possamos admitir que, conforme Hadot e Foucault, os vínculos afetivos sejam capazes de conduzir a vida à experiência do presente na medida em que o ato de amar consiste no movimento que relaciona um amante ao outro e no movimento que os relaciona ao mundo. Nesse sentido, ambos os autores parecem se atrelar à antiga discussão entretida pelos estoicos acerca do tempo. Como nos explica Émile Bréhier, a duração do presente se delimita pela presença do ato que incide causalmente sobre o si, o outro e o mundo: "o presente não é, portanto, momentâneo, pois ele dura tanto quanto o ato, mas é limitado enquanto o próprio ato." (BRÉHIER, 2012, p.102) De modo geral, para estoicos o tempo concerne à dimensão de todo e qualquer movimento que nos atrela à movimentação do mundo. Como explica Simplício: "No que concerne aos estoicos, Zenão diz que o tempo é a dimensão de todo e qualquer movimento, ao passo em que Crisipo diz que o tempo é a dimensão do movimento do mundo." 2 No estoicismo, a experiência do presente está imbricada ao movimento das ações por meio das quais os indivíduos se entrelaçam física e eticamente, pois a modificação do êthos se faz em razão da disponibilidade causal do si mesmo, isto é, em decorrência da capacidade deste para agir sobre si e sobre os outros, mas também para sofrer a interferência de suas próprias ações ou de ações externas. ${ }^{3}$ Ademais, o tempo presente representa as mudanças instauradas no e pelo mundo, já que as transfigurações éticas do si e do outro são capazes de incidir em menor ou maior proporção sobre o cosmos. Isso significa que o mundo está disposto de certa forma em relação aos indivíduos que o constituem e que estes estão dispostos de certa forma em relação ao mundo que os abarca. ${ }^{4} \mathrm{O}$ presente

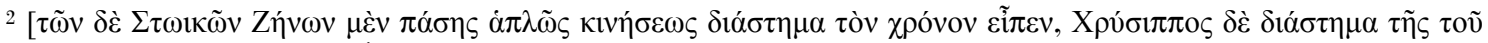

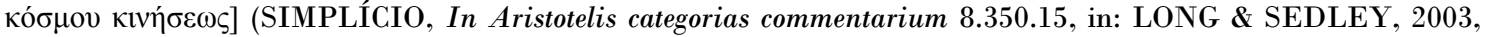
Vol.2, p.301, tradução nossa)

3 "O termo 'causa' aplica-se unicamente a um corpo que esteja ativamente envolvido em algum processo ou seja responsável por algum estado. Essa restrição também explica um aspecto da teoria estoica que a princípio é de compreensão difícil, a saber, sua distinção peculiar entre causa (aítion) e efeito (apotelésma). Embora essa distinção nos pareça componente natural de qualquer língua, ela não só foi invenção dos estoicos, seita relativamente tardia de filósofos da Era Helenística, como também tinha para eles sentido especial. Ao contrário do que se possa imaginar, o efeito não é o próprio corpo atingido, mas meramente alguma mudança ou diferença de estado nesse corpo. Os efeitos são, portanto, classificados como estados incorpóreos das coisas. Como explica Sexto Empírico (M IX 211): "um corpo, como uma faca, torna-se para um corpo, a carne, a causa de um predicado incorpóreo (kategórema), a saber, ser cortado; ou, por outro lado, um corpo, o fogo, torna-se para um outro corpo, a madeira, a causa do predicado ser queimado.' Pondo a parte a questão a respeito de por que os estoicos associam as mudanças ou efeitos a predicados, fica claro que tais efeitos incorpóreos em si mesmos não podem agir como causas de mudanças em outros corpos." (FREDE, 2006, p.209-210)

4 "Obviamente [conforme o estoicismo] as partes do mundo, inclusive nós mesmos, são causalmente atingidas, como corpos, por seus vizinhos físicos, mas, sob outra descrição, elas são de algum modo mudadas, embora não haja alteração interna por tudo o que acontece em qualquer parte do mundo." (BRUNSCHWIG, 2006, p.256)
}

STEPHAN. Cassiana Lopes. Como não esquecer de viver o presente: um ensaio sobre a espiritualidade do amor. Griot : Revista de Filosofia, Amargosa - BA, v.18, n.2, p.375-396, dezembro, 2018. 
corresponde aos pontos que resultam de tais entrelaçamentos e que arrematam o acontecimento transfigurador atinente aos movimentos de amor por si, pelos outros e pelo mundo. Em outras palavras, de acordo com a terminologia estoica, o presente se classificaria como o estado incorpóreo que denota tanto a transformação ética de si e do outro quanto a modificação política do mundo, de tal modo que o amor se constitui como a ação que movimenta estes três elementos e que estabelece o vínculo entre eles.

Aparentemente influenciados pelo estoicismo, Hadot e Foucault nos mostram que não estamos necessária e simplesmente fadados à presença do presente, ou melhor, a sua experiência, como diria Epicteto, concerne à instância de tudo aquilo que depende de nós, e não à realidade do que independe do nosso esforço. ${ }^{5}$ Como veremos, a condução do si mesmo em direção ao presente não diz respeito a uma tarefa individualista egoísta, a qual envolveria o recalque da influência dos outros sobre o movimento de transformação do si. Da mesma maneira, o tempo presente não está necessariamente dado à vida dos indivíduos, pois se o concebemos como uma intuição que predetermina a nossa relação com o mundo, corremos o risco de recalcar o fato de que viver o presente ou se colocar em presença do presente também depende do esforço ético do si mesmo. A experiência do presente manifesta ao mesmo tempo a faceta social e individual da vida no mundo, e talvez possamos afirmar que Hadot e Foucault tenham detectado, ao retomarem a antiga definição da filosofia como arte de viver, a crise relativa a este paroxismo que constitui a existência voltada ao presente. Por um lado, mediante o isolamento do indivíduo à privacidade de sua introspecção, deparamo-nos com a redução da vida à saudade e ao arrependimento em relação àquilo que fora feito, ou seja, neste caso o indivíduo, conformando-se aos limites da casa, resguarda-se do mundo e se enfraquece social e politicamente. Por outro lado, na completa exposição da existência à demanda e à proteção social dos outros ou do Outro, defrontamo-nos com a progressiva destruição da subjetividade e com a iminente redução da vida à busca por um futuro no qual os sujeitos seriam impedidos de intervir distintamente no mundo e no qual o engajamento ético do indivíduo em relação à transformação de sua realidade psíquica e pessoal seria desvalorizado como politicamente irrelevante para a modificação da sociedade. ${ }^{6}$ A crise ético-política que nos arrebata revela a desarticulação entre a vida e o presente, denunciando o seu aprisionamento no saudosismo culposo do passado ou na ansiedade correlata a um futuro incerto. Como nos explica Hadot, "o passado não depende mais de nós porque foi definitivamente fixado, o futuro não depende de nós porque ele ainda não é." (HADOT, 2008, p.52, tradução nossa) Estamos sufocados por tudo aquilo que foi e por tudo aquilo que

\footnotetext{
5 “Entre os entes, há os que dependem de nós e os que não dependem de nós. Aquilo que depende de nós: julgamento, impulso, desejo, repulsa, em uma palavra, tudo que diz respeito ao nosso próprio esforço. Aquilo que não depende de nós: o corpo, a propriedade, as opiniões que outros possuem de nós, os cargos públicos e tudo o

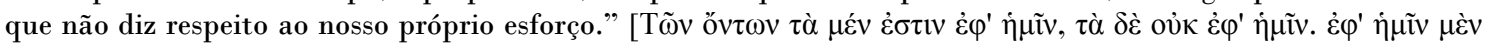

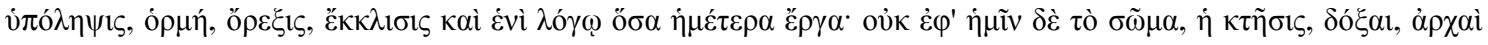

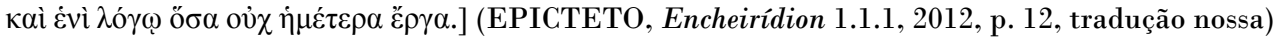

${ }^{6}$ Sobre o paroxismo que constitui a existência voltada ao presente, relativo à faceta ao mesmo tempo social e individual da vida no mundo, cf. Qu'est-ce qu'une vie bonne? (BUTLER, 2014).
}

STEPHAN. Cassiana Lopes. Como não esquecer de viver o presente: um ensaio sobre a espiritualidade do amor. Griot : Revista de Filosofia, Amargosa - BA, v.18, n.2, p.375-396, dezembro, 2018. 
ainda não é, de maneira que não conseguimos nos mover e muito menos modificar a circunstância de nossas vidas. A nossa falta de movimento parece estar, de alguma forma, relacionada com a nossa incapacidade de agir e de sofrer, de amar e de ser amado, isto é, de existir na centelha das espadas que entrelaçam o individual e o social. Nesse sentido, o enigma que agora se impõe reúne duas questões, uma negativa e outra positiva: Por que não podemos nos mover? Como podemos nos mover?

\section{Dos movimentos em direção ao presente: éros e áskesis}

A diferença concernente ao estatuto filosófico do presente em Hadot e Foucault parece se atrelar ao quadro daquilo que este designou por "espiritualidade" e não ao da "filosofia", majoritariamente concebida, na modernidade, como o pensamento responsável por fundar o método capaz de garantir a aquisição do conhecimento por parte do sujeito previamente determinado como substância racional. Em contraposição a tal noção de filosofia, a espiritualidade, cuja tradição remonta às filosofias da Antiguidade greco-romana, pergunta pelo preço ético e político que o sujeito precisa pagar para ter acesso à verdade. (FOUCAULT, 2010, p.15) Isso significa que Hadot e Foucault não se diferenciam pela definição analítica do presente, mas sim pela forma como compreendem a vivência da dimensão temporal que abarca a transformação do si em relação a si mesmo, aos outros e ao mundo. Mais precisamente, Hadot e Foucault se distinguem quanto à experiência do acesso do sujeito à verdade que o circunda e o significa no âmbito de sua modificação ético-política. De acordo com Foucault, no caso da espiritualidade "a verdade só é dada ao sujeito a um preço que põe em jogo o ser mesmo do sujeito. Pois, tal como ele é, não é capaz de verdade." (Idem., p.16) A referida transformação do sujeito, demandada no exercício da espiritualidade, corresponde à "forma de um movimento que arranca o sujeito de seu status e de sua condição atual." (Idem.) A atualidade atinente à condição da qual o sujeito é arrancado não concerne à experiência do tempo presente, pois esta se faz, como apontamos acima, pela experiência do ato de transfiguração. Sendo assim, talvez possamos afirmar que o sujeito é arrancado, através de sua dedicação ao movimento de modificação do si, daquela condição atual de inércia que, ao aprisioná-lo à fixidez do passado e à expectativa do futuro, impede-o de viver o presente. Segundo Foucault, historicamente existem dois movimentos que buscam liberar o si da estagnação ético-política e que visam, portanto, habilitar o seu acesso à verdade. Trata-se do movimento ascensional e do movimento ascético, os quais também podem ser denominados, em referência às filosofias greco-romanas, éros e áskesis:

[...] (movimento de ascensão do próprio sujeito; movimento pelo qual, ao contrário, a verdade vem até ele e o ilumina). Chamemos esse movimento, também muito convencionalmente, em qualquer que seja seu sentido, de movimento do éros (amor). Além dessa, outra forma pela qual o sujeito pode e deve transformar-se para ter acesso à verdade é um trabalho. Trabalho de si para consigo, elaboração de si para consigo, transformação

STEPHAN. Cassiana Lopes. Como não esquecer de viver o presente: um ensaio sobre a espiritualidade do amor. Griot : Revista de Filosofia, Amargosa - BA, v.18, n.2, p.375-396, dezembro, 2018. 
progressiva de si para consigo em que se é o próprio responsável por um longo labor que é o da ascese. Éros e áskesis são, creio, as duas grandes formas com que, na espiritualidade ocidental, concebemos as modalidades segundo as quais o sujeito deve ser transformado para, finalmente, tornarse sujeito capaz de verdade. (FOUCAULT, 2010, p.16).

Com efeito, a espiritualidade do amor não se atrela apenas ao movimento do éros, ou seja, o movimento da áskesis também se constitui pelo esforço do si mesmo em torno do afeto por si, pelos outros e pelo mundo, pois em ambos os casos, através do amor o si transforma o seu próprio êthos e se torna capaz de interferir politicamente no cosmos. Em outras palavras, a intenção de Foucault quando faz uso do termo "éros" para denotar o movimento ascensional do si em direção ao presente não é a de desvincular o amor da áskesis para vinculá-lo exclusivamente à experiência da ascensão. Foucault nos mostra que o éros e a áskesis correspondem a dois modos distintos de se experimentar o amor como um movimento que entrelaça o si, os outros e o mundo e, assim, a duas maneiras diversas de se vivenciar o presente. A partir disso, talvez possamos afirmar que o movimento do éros remonta prioritariamente à tradição socrático-platônica dos exercícios filosóficos, para a qual o amor do si por si mesmo, pelos outros e pelo mundo se fundaria no amor originário pelo Divino. A ascensão do si mesmo em relação à Verdadeira Beleza revela a verdade concernente à essencialidade da identificação entre a razão humana e a razão divina, de maneira a fundamentar o fluxo erótico que, sob a lógica narcísica do espelho, aproxima o si, o outro e o mundo. $\mathrm{O}$ movimento do éros parece instaurar e repousar sobre o narcisismo que articula a reciprocidade do amor à simetria essencial entre os amantes. Estes buscam em si mesmos o reflexo da beleza divina, ou melhor, o desejo de amar seria despertado pela divindade que pode ser refletidamente contemplada pelo si através do olhar do outro que lhe serve de espelho e que, enquanto tal, lhe revela a perfeição, a plenitude e a eternidade da união entre a alma humana e a divina. Como nos explica Jean-Pierre Vernant, cada um "serve ao outro de espelho, onde no olho daquele que o defronta é o reflexo redobrado de si mesmo que se percebe e que se persegue no desejo." (VERNANT, 2011, p.160, tradução nossa) $\mathrm{O}$ amor vivido no âmbito do movimento ascensional possui uma estrutura triangular unitiva, isto é, o afeto do si pelos outros é condicionado ao amor pelo divino que se constitui como parâmetro normativo da transformação ética dos amantes. Nesse sentido, o êxtase erótico representaria o genuíno desejo que os amantes possuem pela fusão com o radicalmente Outro, escondido no fundo da alma daquele belo corpo com o qual o si se relaciona afetuosamente. Como nos mostra Vernant, "somente este 'outro' radical pode fundar o valor erótico do meu semelhante e o meu próprio, tornando-nos belos um para o outro e cada um para si porque iluminados, os dois, por uma mesma luz, aquela que projeta a fonte inesgotável de toda a beleza." (Idem., p.167, tradução nossa) Ademais, segundo Foucault, o movimento do éros é transcendental e circular, visto que o si mesmo se ultrapassa para aceder ao divino e, simultaneamente, retornar a si de modo a se constituir por assimilação ao Outro que o rege na racionalidade:

STEPHAN. Cassiana Lopes. Como não esquecer de viver o presente: um ensaio sobre a espiritualidade do amor. Griot : Revista de Filosofia, Amargosa - BA, v.18, n.2, p.375-396, dezembro, 2018. 
[...] ter acesso à verdade é ter acesso ao próprio ser, acesso este em que o ser ao qual se tem acesso será, ao mesmo tempo e em contraponto, o agente de transformação daquele que a ele tem acesso. É este o círculo platônico ou, em todo caso, o círculo neoplatônico: conhecendo a mim mesmo, acedo a um ser que é a verdade, e cuja verdade transforma o ser que eu sou, assimilando-me a Deus. A homoíosis tô theô aí está presente. (FOUCAULT, 2010, p.173).

Em distinção ao éros, o movimento da áskesis parece se referir principalmente à cultura de si vigente nas filosofias do período helenístico-romano. Conforme Foucault, de modo geral a áskesis cínica, estoica e epicurista rompem com o caráter do movimento do éros instaurado pela tradição socrático-platônica, porque o trabalho ascético de si para consigo não se articula à prática do amor estruturado na triangulação unitiva, que conecta o si ao outro em virtude do desejo incondicional pelo divino, e porque a ascese não se delineia como um movimento transcendental circular. A partir das interpretações que Foucault dedica ao cuidado de si estoico, somos capazes de perceber que a áskesis concerne ao "movimento pelo qual, sem nunca perder de vista este mundo e, no seu interior, nós e o que aí somos, é-nos [permitido] apreendê-lo em sua globalidade." (FOUCAULT, 2010, p.253) Nesse sentido, talvez possamos afirmar que o amor vivenciado asceticamente incita e é incitado pela verdade relativa à pluralidade do mundo constituído por corpos peculiarmente qualificados, os quais, ao mesmo tempo, manifestam e estabelecem entre si continuidades e rupturas identitárias. ${ }^{7} \mathrm{O}$ acesso à verdade acerca da pluralidade do cosmos não depende da contemplação do divino pelo olhar do amante que o reflete, mas sim da multiplicação das interações sociais através da exercitação da crítica em relação aos valores vigentes que incidem sobre o si, os outros e o mundo. Como nos mostra Foucault, "crítica, pois, da primeira infância e das condições em que ela se desenrola. Crítica também do meio familiar. (...) Em terceiro lugar, finalmente, (...) toda a crítica da formação pedagógica dos mestres." (FOUCAULT, 2010, p.87) A espiritualidade ascética do amor não se atrela à lógica narcísica do espelho, já que o outro com o qual o si se relaciona criticamente não manifesta a essencialidade da identificação entre a razão humana e a divina, mas representa, a partir de sua complexa disposição, uma diversidade de qualidades que simultaneamente o distanciam e o aproximam do si. Ao se defrontar e cuidadosamente se entrecruzar com as diferenças do outro, o si dedicado à ascese transgride os seus próprios limites de modo a tornar-se o que até então não havia sido no mundo. (FOUCAULT, 2010, p.87) No caso da áskesis, a reciprocidade do amor repousa sobre a mútua possibilidade da diferença entre o si e o outro, ao invés de se vincular, como no âmbito do éros, à mútua possibilidade da fusão com o radicalmente Outro. Isso não quer dizer que a peculiaridade do outro com o qual o si

\footnotetext{
7 “[...] no caso das disposições complexas existem as formas individuais, em referência às quais os estoicos falam do peculiarmente qualificado, que concerne ao mesmo tempo ao que é adquirido e destruído, bem como ao que

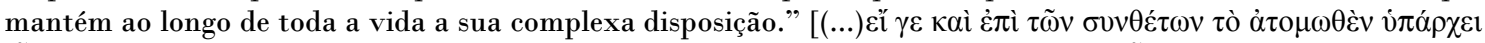

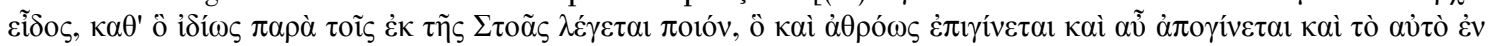

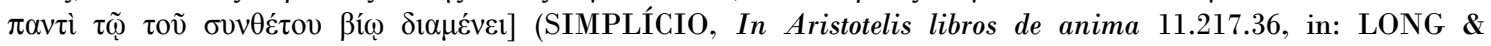
SEDLEY, 2003, Vol.2, p.173, tradução nossa)
}

STEPHAN. Cassiana Lopes. Como não esquecer de viver o presente: um ensaio sobre a espiritualidade do amor. Griot : Revista de Filosofia, Amargosa - BA, v.18, n.2, p.375-396, dezembro, 2018. 
se relaciona exclui a experiência da igualdade. Com efeito, ela se faz tanto pela vivência das qualidades que por vezes identificam o si e os outros, quanto pela percepção de que o mundo é comum e plural porque compartilhado entre e por corpos igualmente peculiares. ${ }^{8}$ Desse modo, explica-nos Foucault, o movimento da áskesis se situou no cerne do cuidado de si helenístico-romano que se constituiu como "uma prática social, dando lugar a relações interindividuais, a trocas e comunicações e até mesmo a instituições; ele proporcionou, enfim, um certo modo de conhecimento e a elaboração de um saber." (FOUCAULT, 2011, p.50).

Com base nessas considerações acerca da espiritualidade como éros e da espiritualidade como áskesis, talvez possamos afirmar que a interpretação hadotiana dos exercícios espirituais os circunscreve na tradição do éros socrático-platônico, ao passo em que a interpretação foucaultiana da estética da existência a atrela à cultura da áskesis helenístico-romana. Para Hadot, a intrínseca conexão entre a filosofia estoica e a literatura de Goethe se fundamentaria na atitude universal instaurada pelo éros na história da filosofia. Hadot nos explica que o éros dá à busca pela transformação de si "o caráter de uma experiência vivida, viva, de uma presença" eterna e fundamental, e que isto "é verdadeiro para Platão, mas também para toda filosofia" como arte de viver. (HADOT, 2001, p.204, tradução nossa) Ademais, conforme Hadot, o tema concernente ao movimento ascensional em direção ao presente foi descrito pelas filosofias da Antiguidade greco-romana e retomado "em abundância por toda a literatura ocidental, notadamente por Pascal, Voltaire, André Chernier, [e] sobretudo por Goethe." (Idem., p.263, tradução nossa) Diferentemente, Foucault entrevê a furtiva conexão entre a filosofia estoica e o dandismo de Baudelaire em virtude da atitude crítica inaugurada por ocasião da áskesis helenístico-romana. Segundo Foucault, o tema do movimento ascético do si mesmo em direção ao presente nunca foi tão forte quanto na época helenística e romana; entretanto, "podemos reler toda uma vertente do pensamento do século XIX como a difícil tentativa, ou uma série de difíceis tentativas, para reconstituir uma ética e uma estética do eu. Tomemos, por exemplo, Stirner. Schopenhauer, Nietzsche, o dandismo, Baudelaire, a anarquia, o pensamento anarquista, etc., e teremos uma série de tentativas [...]." (FOUCAULT, 2010, p.224) A partir disso, somos capazes de perceber que o interesse de Hadot pelo estoicismo reside, acima de tudo, nas possíveis continuidades entre esta filosofia e o platonismo, ao passo em que Foucault, como nos mostra Thomas Bénatouil, parece se interessar principalmente pelo "antiplatonismo da filosofia helenística e, em particular, do estoicismo. Para Foucault, o platonismo representa a subordinação do cuidado de si a um conhecimento de si totalizante que implica na conversão a um real transcendente." (BÉNATOUÏL, 2003, pp. 30-31, tradução nossa) Por certo, não discutiremos em nosso ensaio os pormenores relativos às diferenças histórico-metodológicas sobre as quais repousam as interpretações de Hadot e Foucault acerca dos enlaces entre a filosofia como arte

\footnotetext{
${ }^{8}$ Crisipo, no segundo livro Sobre o movimento, diz: “o mundo é um corpo completo, as suas partes não são completas, pois estão dispostas de certo modo em relação ao todo e não são por si mesmas." [ [ $\tau \varepsilon ́ \lambda \varepsilon \delta 0 \nu \mu \varepsilon \dot{\nu} \nu$

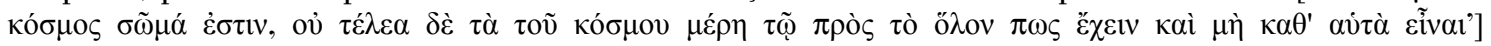
(PLUTARCO, De Stoicorum Repugnantiis 1054.F.1, in: LONG \& SEDLEY, 2003, Vol.2, p.179, tradução nossa)
}

STEPHAN. Cassiana Lopes. Como não esquecer de viver o presente: um ensaio sobre a espiritualidade do amor. Griot : Revista de Filosofia, Amargosa - BA, v.18, n.2, p.375-396, dezembro, 2018. 
de viver na Antiguidade e na Modernidade. ${ }^{9}$ Contudo, para que possamos compreender a diferença entre a experiência do tempo presente no que tange aos exercícios espirituais e à estética da existência, não poderíamos deixar de mencionar a influência do platonismo sobre a leitura hadotiana acerca do estoicismo e de toda a tradição filosófico-literária dos exercícios espirituais, bem como a valorização interpretativa, por parte de Foucault, do anti-platonismo atrelado ao estoicismo e à cultura que se esboça, através da história, como a série das difíceis tentativas para reconstituir uma estética e uma ética do eu. ${ }^{10}$ Doravante, vejamos como a antiga tradição dos exercícios espirituais e a antiga cultura da estética da existência interferem na maneira pela qual Hadot e Foucault circunscrevem na modernidade o enigma que move o nosso ensaio, a saber, aquele que pergunta pela experiência do tempo presente.

\footnotetext{
${ }^{9}$ A diferença vinculada à atitude universal dos exercícios espirituais, que remonta ao éros platônico, e a atitude crítica da estética da existência, que remonta à áskesis do cuidado de si helenístico-romano, recai sobre a maneira pela qual Pierre Hadot e Michel Foucault entrecruzam historicamente a Antiguidade e a Modernidade, e sobre o modo pelo qual ambos postulam a prática dos exercícios espirituais e da estética da existência ao homem contemporâneo. Mais precisamente, a partir dos exercícios espirituais Pierre Hadot elabora uma experiência universal ou universalizante da história da filosofia ocidental, enquanto que a partir da estética da existência Michel Foucault desenvolve uma experiência singular e contingente da historicidade concernente às diversas verves filosóficas do Ocidente. Como nos explica Lorenzini, os exercícios espirituais desencadeiam práticas suprahistóricas, e a estética da existência práticas trans-históricas, relativamente aos enlaces entre a Antiguidade e a Modernidade no que se refere à filosofia como arte de viver. Por um lado, para Hadot "os exercícios espirituais acabam sendo, em realidade, práticas nem tanto trans-históricas, mas supra-históricas: seu valor e seus efeitos concretos não se dobram às leis da história, eles permanecem, ao contrário, universais, e isso porque eles estão enraizados na 'natureza' humana." (LORENZINI, 2014, p.317, tradução nossa) Por outro lado, Foucault está “convencido da importância de insistir sobre as descontinuidades históricas, e isso nem por 'amor' às descontinuidades enquanto tais, nem a fim de negar a existência de certos processos ou continuidades transhistóricos, mas precisamente por guardar sempre no espírito que seria necessário estudar cada forma de experiência em sua singularidade e em sua contingência." (Idem., p.321, tradução nossa) Sobre este assunto cf. também a dissertação de mestrado intitulada Michel Foucault e Pierre Hadot: um diálogo contemporâneo sobre a concepção estoica do si mesmo (STEPHAN, 2015, pp.41-82).

10 Não temos por objetivo averiguar qual das leituras, se a de Hadot ou a de Foucault, é filosófica e filologicamente mais fidedigna ao estoicismo, já que estamos interessados, sobretudo, em compreender as ressonâncias ético-políticas das respectivas interpretações sobre a vida na contemporaneidade. Contudo, faz-se importante ressaltar que as duas reconstruções históricas em relação ao estoicismo são possíveis, ou seja, tanto a hadotiana, que conecta a filosofia estoica à tradição platônica do éros, quanto a foucaultina, que privilegia a singularidade do estoicismo em relação ao platonismo, enfatizando a influência do cinismo sobre a áskesis estoica. Com efeito, "a filosofia estoica surge em consonância ao cinismo, visto que Zenão de Cício, o fundador da escola estoica, era discípulo do cínico Crates. Sendo assim, o estoicismo ortodoxo subverte algumas estruturas do platonismo, tanto no que tange à relação entre as convenções sociais e a atitude ética, quanto no que concerne ao modo de conhecer e a finalidade da sabedoria. Entretanto, em meados do séc. II a.C. a filosofia estoica se integrou ao platonismo. De fato, esta fase do estoicismo modificaria o caráter futuro da ética estoica e o sintoma desta mutação repercutiria no estoicismo romano de Cícero, o qual se dedicou à elaboração de uma teoria dos deveres cuja rigidez se estabeleceria, por um lado, em virtude do conhecimento do Todo e, por outro lado, com o auxílio da institucionalização das prescrições morais que se fundam na Razão." (STEPHAN, 2015, pp.117-118) Esta ligeira esquematização histórica do estoicismo nos permite perceber, de modo geral, (1) aquilo que Hadot e Foucault privilegiam na Antiguidade filosófica, (2) em qual perspectiva ambos circunscrevem suas análises sobre o estoicismo e (3) sob qual prisma filosófico Hadot e Foucault desenvolvem suas próprias interpretações acerca do aporte ético-político dos exercícios espirituais e da estética da existência na contemporaneidade.
}

STEPHAN. Cassiana Lopes. Como não esquecer de viver o presente: um ensaio sobre a espiritualidade do amor. Griot : Revista de Filosofia, Amargosa - BA, v.18, n.2, p.375-396, dezembro, 2018. 


\section{Viver o tempo presente: entre o ideal e a ficção}

P. Hadot e M. Foucault, como mostramos no início de nosso ensaio, parecem ser igualmente influenciados pela concepção estoica de que a vivência do tempo presente diz respeito à experiência da dimensão do movimento do si em relação ao outro e destes em relação ao mundo. Se assim for, talvez possamos afirmar que ambos concordariam com o estoicismo no que se refere à formulação segundo a qual o tempo presente consiste no estado incorpóreo que resulta do acontecimento relativo ao entrelaçamento afetuoso entre o si, o outro e o mundo e que, enquanto efeito do ato de amar, o presente denota a transformação ético-política destes três elementos. Além disso, Hadot e Foucault parecem se inspirar no estoicismo quando associam a experiência do presente à preparação ética do sujeito para a aquisição da verdade. $O$ presente é presenciado pelo sujeito na medida em que este se esforça na busca pela boa vida e, simultaneamente, na busca pela verdade que envolve e significa a sua transfiguração. Isso quer dizer que, conforme os estoicos, nem toda a mudança enfrentada no decorrer da existência consiste em um movimento em direção ao presente, ou seja, certas mutações somáticas pelas quais os indivíduos passam, sejam elas provenientes de intervenções fortuitas ou não fortuitas, não estão necessariamente atreladas ao movimento capaz de conduzi-los ao presente. As transformações concernentes à constituição física dos indivíduos são abarcadas pela dimensão do tempo presente quando vivenciadas em relação à espiritualidade do amor, cuja prática, ascensional no caso de Hadot, ou ascética no caso de Foucault, permite que o si elabore o amor por si mesmo e, assim, aproprie-se das diversas constituições que perpassam a sua existência.

De acordo com Sêneca, "cada período da vida tem sua própria constituição, uma para o bebê, outra para a criança, outra para o jovem e outra para o velho." (SÊNECA, Ad Lucilium epistulae morales 121.15, in: LONG \& SEDLEY, 2003, Vol.1, p.347, tradução nossa) Contudo, a partir da juventude, as mudanças que abarcam a constituição do indivíduo só são dimensionadas pelo presente quando circunscritas no âmbito da movimentação ética do si mesmo. Apenas desse modo os indivíduos adultos se tornam capazes de se vincular "apropriadamente àquela constituição na qual existem." (Idem.) Hadot, em consonância com o estoicismo, explica-nos que as crianças se atrelam espontaneamente ao tempo presente. A alta sabedoria atinente à vida que vive o presente consiste, segundo Hadot, em uma sabedoria infantil, de tal forma que, "para Goethe, 'a saúde do momento' dos antigos torna-se aqui uma sabedoria de criança, isto é, uma disposição espontânea para viver no presente e acolhê-lo com alegria sem refletir, sem procurar compreender." (HADOT, 2008, p.77, tradução nossa) Foucault também nos mostra que o movimento em direção ao presente se torna, na medida em que envelhecemos, um esforço que afirma, desde os primórdios da ansiedade juvenil pelo futuro até o termo da velhice que insiste em saudosamente se fixar no passado, a necessidade do cuidado filosófico em relação a si mesmo como "uma obrigação permanente que deve durar a vida toda." (FOUCAULT, 2010, p.80) Ademais, no início da Ética Elementar, o estoico Hierocles nos explica que o mundo, de um ponto de vista físico, consiste no

STEPHAN. Cassiana Lopes. Como não esquecer de viver o presente: um ensaio sobre a espiritualidade do amor. Griot : Revista de Filosofia, Amargosa - BA, v.18, n.2, p.375-396, dezembro, 2018. 
desdobramento do pneuma, o qual dá aos corpos a capacidade da ação. O pneuma não se espalha da mesma maneira em todos os lugares, ou seja, ele não confere consciência e razão a todas as coisas. Sendo assim, nos seres inanimados o pneuma

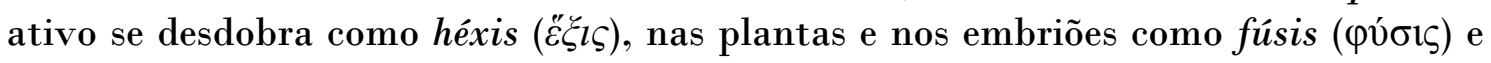
nos animais como psiché ( $\psi v \chi \eta ́)$. A variação quantitativa do pneuma ativo desencadeia a diferença qualitativa de cada um dos grupos descritos acima no que tange à capacidade de intervir ativamente no mundo, de tal modo que os animais, por exemplo, possuem uma capacidade de ação maior do que as plantas, as quais são majoritariamente constituídas pela matéria responsável pelo caráter passivo dos corpos e não pelo pneuma. Estas diferenças gerais que acompanham a vida no cosmos também concernem à vida do animal:

\begin{abstract}
O embrião certamente por todo o tempo (falo, pois, do tempo da concepção até o nascimento) permanece fúsis, a qual é um pneuma que, tendo deixado de ser semente, procede sistematicamente do começo ao fim; nos primeiros momentos do tempo a fúsis é um pneuma denso e bastante afastado da psiché, então quando chega perto do nascimento, afina-se, sendo lançada [para o ambiente] por atividades contínuas e com respeito à quantidade corresponde à psiché. Quando chega ao fim, portanto, adaptando-se ao ambiente exterior, a psiché se completa, já que a fúsis é fortalecida pelo ar circundante para se transformar em psiché. ${ }^{11}$
\end{abstract}

Nesta passagem Hierocles nos explica, em primeiro lugar, que o embrião é peneumaticamente fúsis e que, enquanto tal, ele se assemelha a uma planta; em segundo lugar, ele nos indica que a psiché se forma a partir de uma transformação (reorganização) da fúsis e que a alma da criança ainda não é racional. Mais precisamente, conforme Hierocles, tornar-se adulto corresponde a adquirir uma organização psíquica racional, pois a criança dispõe de uma psiché cujo arranjo pneumático não-racional a assemelha aos animais não-humanos. Portanto, o escopo da vida da criança não envolve o esforço ético em direção ao presente, mas abarca a presença espontânea do presente. A mudança da alma da criança para a alma adulta não diz respeito a um ciclo cronológico absoluto que se aplica universalmente à realidade de todo e qualquer animal humano. Para estoicos, a mudança pneumática da alma da criança para a alma adulta depende da forma pela qual o si mesmo interage com o ambiente que o circunda e, sobretudo, da forma pela qual este incide sobre o si mesmo. De modo geral, a espontaneidade infantil relativa à vivência do presente não se deve meramente ao estatuto da constituição pneumática da alma da criança, já que a manutenção ou modificação desta também se articula à maneira pela qual o ambiente incide ética e politicamente na referida vida, dando-lhe ou não condições para a apropriada experiência da infância e para a apropriada experiência

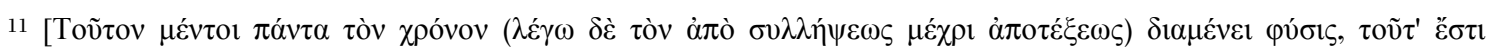

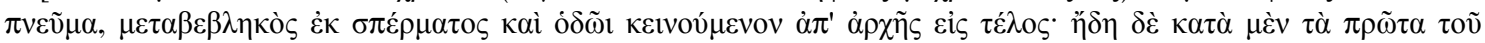

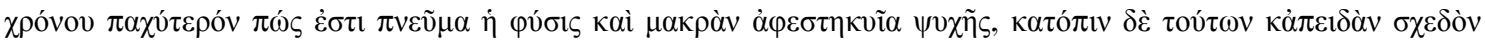

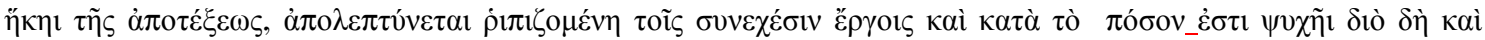

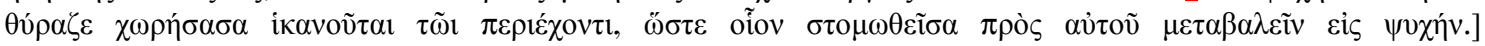
(HIEROCLES, Ethikè Stoicheíosis 1a11, 2009, p.2, tradução nossa)

STEPHAN. Cassiana Lopes. Como não esquecer de viver o presente: um ensaio sobre a espiritualidade do amor. Griot : Revista de Filosofia, Amargosa - BA, v.18, n.2, p.375-396, dezembro, 2018. 
do amadurecimento. Tornar-se adulto consiste em um processo de rearranjo pneumático da alma que se articula à diferença de atitude dos outros em relação ao si e deste em relação a si mesmo, pois o si se torna adulto na medida em que toma consciência de sua estrutura psíquica, responsabilizando-se eticamente pela própria vontade e, desse modo, relacionando-se com os outros e com o mundo com base na distinção daquilo que depende e não depende de seu esforço racional. Parece ser, portanto, neste sentido que o esforço relativo ao movimento capaz de direcionar o si mesmo ao presente consiste, para Hadot e para Foucault, em uma demanda cuja latência marca o início da vida adulta, visto que esta perderia a espontaneidade relativa à presença do presente e a espontaneidade concernente à experiência do amor. Com base nisso, a partir de agora, vejamos como Hadot e Foucault compreendem a moderna recontextualização do antigo elogio estoico à atitude da criança em relação ao tempo presente.

\section{O Ideal}

Para P. Hadot, a criança vivencia quase que inconscientemente a excepcionalidade do instante presente, de tal modo que a sua atitude em relação à trivialidade da vida se manifesta como um amor puro e irrefletido pela natureza do Todo. A inocência da criança no que concerne à afirmação cotidiana do presente revela, de acordo com Hadot, "uma dimensão mística do estoicismo. [Como a criança], a cada momento, a cada instante, é preciso dizer sim ao universo (...)." (HADOT, 2008, p.58, tradução nossa) Hadot nos explica que esta mística estoica, atrelada à tradição socrático-platônica do éros, teria sido recuperada pelo neoplatonismo e modernamente retomada por Goethe que consideraria, "como Plotino, que a saúde é inconsciente, pois ela é conforme a natureza, e que a consciência corresponde a um estado de perturbação, a um estado de doença: quanto mais uma atividade é pura e intensa, menos ela é consciente." (Idem., p.36, tradução nossa) Segundo Hadot, Goethe representaria o misticismo daquela antiga sabedoria de traços infantis pelo convite que Fausto dirige a Helena, a qual evoca "a figura da Beleza antiga, e finalmente da Beleza da Natureza." (Idem., p.16, tradução nossa) Quando ambos dialogam extasiados um pelo amor do outro, Fausto convida Helena a se abandonar inconscientemente ao destino que os une, incitando-a a presenciar no instante presente a eternidade do tempo e a totalidade do espaço. Helena diz a Fausto: "Tão desgastada sinto-me e tão nova, unida a ti, o estranho, a toda prova." E Fausto responde a Helena: "Não negues um destino único e inebriante! Ser é dever, e fosse um só instante." (GOETHE, 2011, Fausto II, verso 9.415, p.407) Como podemos perceber, conforme Hadot, o elogio de Goethe à espontaneidade da criança parece repousar na facilidade que esta tem para desfrutar do presente e para se conformar ao Destino que determina a conjuntura de sua realidade. Em outras palavras, a criança ama com pureza a trivialidade que a circunda e, nesse sentido, obedece despretensiosa e inconscientemente aos desdobramentos da Natureza universal.

STEPHAN. Cassiana Lopes. Como não esquecer de viver o presente: um ensaio sobre a espiritualidade do amor. Griot : Revista de Filosofia, Amargosa - BA, v.18, n.2, p.375-396, dezembro, 2018. 
De acordo com Hadot, a ingenuidade da criança, a qual engloba a pureza e a obediência, compõe o arquétipo da sabedoria antiga, assim como retomada por Goethe. Isso não significa que Hadot associe o esforço do adulto em direção ao presente à busca pela infância perdida. Para Hadot, viver o presente não é fixar-se no passado, já que resgatar a criança que outrora constituíra o si mesmo não corresponde a estagnar-se em virtude do saudosismo por aquilo que fora vivido na infância, mas consiste em movimentar-se no sentido da reatualização, por e em si mesmo, da pureza do amor que conduz o si à fusão com o Todo e que eterniza o instante no qual a alegria que daí decorre é vivenciada, pois "um instante de felicidade equivale a toda uma eternidade de felicidade." (HADOT, 2008, p.56, tradução nossa) Viver o presente é rememorar, através do reflexo do olhar do outro, o Ideal que fundamenta a realidade do amor e, assim, redescobrir em si mesmo a ingenuidade da criança que obedece com pureza e prontidão à Natureza universal. ${ }^{12}$ $O$ esforço dispendido na adequação deliberada e consciente da vontade à espiritualidade ascensional visa tornar espontânea a relação do si com o ideal que manifesta a Beleza originária. Os exercícios espirituais permitem que o si reconheça, através da experiência do presente como o efeito que se segue do jogo causal entretido no âmbito de um amor narcísico, a presença do ideal no real. Segundo Hadot, é justamente a visão do ideal no real que Fausto encontra em Helena e que, de modo geral, Goethe reencontra nos antigos: "o real, para os antigos, era de alguma forma perante os olhos de Goethe um "real idealizado'." (HADOT, 2008, p.26, tradução nossa) Nesse sentido, o amor entre Fausto e Helena recuperaria a potência atrelada à espiritualidade do éros, na medida em que apresentaria ao homem moderno a possibilidade da vida no presente. Em outras palavras, para Hadot o homem moderno, simbolizado por Fausto, ainda é capaz de se reencontrar com o ideal da Beleza originária e de experenciar a sua presença no presente:

$O$ instante excepcional é um momento intoxicante, no qual a existência se intensifica, no qual nós a alcançamos em seu ápice, como no encontro amoroso vivido por Fausto e Helena. Este instante de êxtase inexprimível dá a impressão de que o tempo parou e de que nós acedemos à eternidade. Nesse instante excepcional de felicidade, o homem pode abandonar-se ingenuamente, mas ele pode também tomar consciência de toda a sua riqueza, de toda a sua significação, vivê-la intensamente, interiorizá-la, nela se engajar completamente, assumi-la por meio do dom voluntário do si mesmo. De fato, quando somos invadidos pela felicidade, notadamente

12 Em Os sofrimentos do jovem Werther, Goethe já parecia associar a inocência da criança à espontaneidade relativa à vivência do presente e à obediência em relação à Natureza. As crianças são capazes de desfrutar inconscientemente do presente, ou melhor, a conquista da tranquilidade da alma não depende do esforço relativo a uma vontade filosófica deliberada e consciente. Ao se deparar com duas crianças, Werther nos descreve: "A primeira vez em que a sorte de um acaso me levou para baixo das tílias, num belo meio-dia, achei aquele lugar tão solitário. Todo mundo havia ido para o campo. Só um rapagote de cerca de quatro anos estava sentado no chão segurando outro, de mais ou menos meio ano, acolhido entre suas pernas, com os dois bracinhos encostados a seu peito, de forma a lhe servir como uma espécie de poltrona. E apesar da vivacidade com que seus olhos negros giravam à volta, estava bem tranquilo. Me causou prazer aquele espetáculo: sentei-me sobre o arado que jazia ali perto, e desenhei com gosto aquela fraterna atitude. [...] Isso só fez fortalecer meu propósito de doravante me prender apenas à natureza. Só ela é infinitamente rica e só ela é que forma os grandes artistas." (GOETHE, 2011, p.26)

STEPHAN. Cassiana Lopes. Como não esquecer de viver o presente: um ensaio sobre a espiritualidade do amor. Griot : Revista de Filosofia, Amargosa - BA, v.18, n.2, p.375-396, dezembro, 2018. 
pelo sentimento do amor, é quase sem refletir e sem querer que nos deixamos absorver pelo presente. [...] $\mathrm{O}$ êxtase amoroso aparece, assim, como um êxtase cósmico. (HADOT, 2008, pp.64-65 e p.68, tradução nossa).

Portanto, no que tange à tradição dos exercícios espirituais, o princípio que prescreve a vida conforme o presente adquire um valor moral que responde às exigências do dever fundamentado na ideia da universalidade da Razão. Conformar a vontade a este preceito moral significa ceder à intenção divina, para qual a tranquilidade ou a salubridade da alma prefigura a finalidade da vida humana. $O$ objetivo do esforço relativo à submissão da vontade a este autêntico dever é o de tornar cada vez mais espontâneo o movimento ascensional que assimila o si ao Divino. Goethe, explica-nos Hadot, teria recontextualizado o movimento do éros ao perceber a urgência da demanda moral que requer a modificação do si mesmo no presente. Para Goethe a ascensão consiste no movimento a partir do qual o si se constitui por identificação ao divino (verselbstigen) e, simultaneamente, desconstituise como um indivíduo distinto à universalidade da Razão (entselbstigen). (HADOT, 2008, p.82) Como nos mostra Hadot, Goethe também parece recuperar, através do tema da ultrapassagem de si, o misticismo dos antigos exercícios espirituais ao afirmar que: "Para se reencontrar no infinito, o indivíduo aceita voluntariamente desaparecer [...]. Abandonar-se é uma voluptuosidade"". (HADOT cita GOETHE, 2008, p.83, tradução nossa) Por conseguinte, parece que para Goethe os amantes, ao trocarem olhares profundos, desnudam-se dos corpos que envelopavam suas almas e ultrapassam os limites de si mesmos, deslocando-se em direção à eternidade do tempo e à totalidade do espaço, ou seja, o Ideal, até então inexplorável, revela-se como a verdade do amor.

Com base na interpretação de Hadot acerca da tradição dos exercícios espirituais, talvez possamos afirmar que a peculiaridade do animal humano em relação aos demais entes do mundo concerne à sua natureza racional, sendo justamente dela que decorre a aptidão ética, essencial a todo e a qualquer ser humano, para experenciar utopicamente o amor e, assim, para vivenciar o presente como a excepcionalidade que revela o ideal no real. Nesse sentido, parece que que, conforme Hadot, a incapacidade para se mover em direção ao presente, manifestada pela maioria dos indivíduos na modernidade, deve-se à desconsideração da Razão universal como o ideal que fundamenta a realidade humana. A desvalorização deste traço fundamental à vida humana impede que os indivíduos experienciem o amor em sua pureza e autenticidade, ou seja, o amor deixa de ser compreendido como um movimento de ascensão e passa a ser praticado como uma atividade que visa a fútil fruição do prazer por parte do si que o obtém egoisticamente. Para Hadot, tornamonos incapazes de sentir o amor que Fausto sentiu por Helena, na medida em que começamos a desconfiar da Beleza originária de Helena e a nos incomodar com a ingenuidade de Fausto, o qual continuava a insistir no alto valor moral e político da obediência à Natureza universal: "Ora, segundo uma tendência quase geral do pensamento moderno, tendência talvez mais instintiva do que refletida, as noções de 'Razão Universal' e de 'natureza universal' não têm mais hodiernamente muito 
sentido." (HADOT, 2017, p.188) Com efeito, o Baudelaire de Foucault, diferentemente do Goethe de Hadot, insere-se no grupo destes que tendenciosamente esvaziaram o sentido da Razão Universal e que dela desarticularam a beleza experenciada no contexto do vínculo amoroso. Contudo, de acordo com Foucault, isso não quer dizer que Baudelaire teria sido incapaz de perceber a urgência da relação entre a transfiguração ética do si mesmo e a experiência do tempo presente. Como veremos a seguir, na medida em que faz parte da história da cultura da estética da existência, Baudelaire oferece ao enigma do tempo presente uma resposta distinta daquela que encontramos em Goethe e na tradição dos exercícios espirituais.

\section{A ficção}

M. Foucault, assim como P. Hadot, também leva em consideração a constatação estoica de que a criança vive espontaneamente o presente. Segundo Foucault, o antigo enaltecimento da disposição infantil para se viver prontamente o presente teria sido retomado por Baudelaire justamente porque este se dedicara à difícil tentativa de recontextualizar, na modernidade, a espiritualidade ascética do amor ético do eu por si, pelos outros e pelo mundo. (FOUCAULT, 2010, p.224) No caso do Baudelaire de Foucault, a criança não seria louvada por sua ingenuidade, como pudemos perceber nas interpretações de Hadot sobre Goethe, mas sim por sua astúcia. Nesse sentido, a espontaneidade da criança para viver o presente repousaria tanto em sua facilidade para desobedecer a ordem vigente na sociedade, a qual era representada pelo Goethe de Hadot como a destinação divina, quanto para exercer a sua singularidade no mundo e, simultaneamente, inebriar-se com a singularidade dos outros, pois, como afirma Baudelaire: “a criança vê tudo como novidade; ela está sempre inebriada." (BAUDELAIRE, 2010, p.25) Portanto, Baudelaire parece se interessar pela atitude espontaneamente astuciosa da criança que desobedece às normas promulgadas pelos adultos iluminados pela ideia da Razão universal. ${ }^{13}$ A astúcia infantil se manifestaria à vida adulta, embrenhada na inércia decorrente da saudade ou do remorso em torno daquilo que já foi feito e da ansiedade em torno daquilo que ainda não é, como o poder ou a aptidão para a liberdade. Como nos mostra Bataille, para Baudelaire a "liberdade seria, a rigor, um poder da criança: ela não seria mais, para o adulto engajado na organização obrigatória da ação, que um sonho, um desejo, uma obsessão." (BATAILLE, 2015, p.33)

\footnotetext{
13 Como observamos anteriormente, Foucault também cita Stirner quando se refere às difíceis tentativas, enfrentadas pelo pensamento do século XIX para reconstituir uma ética e uma estética do eu. Com base nisso, faz-se interessante referenciar Stirner quanto ao elogio que dirige às crianças: "A insubordinação e a teimosia da criança têm tanto direito quanto o seu direito de saber. Dedica-se todo o esforço à estimulação deste último, mas há também que excitar a força natural da vontade à oposição." (STIRNER, 1979, pp.88-89) Isto talvez nos indique uma constante no que tange à cultura da estética da existência, ou seja, aparentemente a insubordinação consiste em uma atitude que perpassa a transhistoriedade da ética do eu. Sendo assim, torna-se possível questionar junto a Foucault se, quando exploramos tal dimensão da estética da existência, "não seríamos reenviados no que concerne à base da atitude crítica a qualquer coisa que corresponderia ou à prática histórica da revolta, da não aceitação de um governo real, ou, por outro lado, à experiência individual da recusa à governamentalidade?" (FOUCAULT, 2015, p.65, tradução nossa)
}

STEPHAN. Cassiana Lopes. Como não esquecer de viver o presente: um ensaio sobre a espiritualidade do amor. Griot : Revista de Filosofia, Amargosa - BA, v.18, n.2, p.375-396, dezembro, 2018. 
Para o Baudelaire de Foucault, o adulto vive o presente quando reatualiza, por meio do movimento ascético, a liberdade vinculada à astúcia infantil de outrora. Mais precisamente, segundo Foucault, a liberdade da criança pode ser retomada pela ascese do adulto na medida em que este movimento se constitui pela prática da crítica, a qual incita à transgressão dos limites do real, cujo nivelamento identitário embota a singularidade da vida dos indivíduos e a diversidade do mundo em virtude do imperativo que prescreve a identificação entre o si e o Outro como o ideal ou a verdade universal, necessária e obrigatória à vida humana. Dessa maneira, a partir de Baudelaire, talvez possamos afirmar que viver o presente corresponde à "necessidade ardente de se prover, dentro dos limites exteriores das conveniências, de uma certa originalidade. [...] Vê-se que, sob certos aspectos, o dandismo confina com o espiritualismo e com o estoicismo." (BAUDELAIRE, 2010, p.63) O adulto que busca pela constituição distintiva de si mesmo é constantemente arrebatado pela curiosidade em relação à pluralidade do mundo, o qual ao mesmo tempo incorpora e é incorporado pela singularidade do outro por quem o si se apaixona quando desobedece a organização narcísica do amor. Assim, o si finalmente se precipita "para o meio dessa multidão, em busca de um desconhecido cuja fisionomia, num relance vislumbrada, tinha-o fascinado. A curiosidade tornara-se uma paixão fatal, irresistível!" (Idem., p.25) O movimento concernente à espiritualidade da áskesis helenístico-romana parece ter sido modernamente retomado por Baudelaire como o movimento da transgressão possível, em distinção à ultrapassagem de si característica dos exercícios espirituais. Como nos mostra Foucault, Baudelaire busca "transformar a crítica exercida na forma da limitação necessária em uma crítica prática exercida na forma da transgressão possível [franchissement possible]." ${ }^{14}$ (FOUCAULT, 2001, p.1393)

A crítica como transgressão possível parece se suceder no âmbito daquela prática da curiosidade fatal e irresistível que vincula o si, ao outro e ao mundo, pois o indivíduo que critica "se interessa pelo mundo inteiro; quer saber, compreender, apreciar tudo o que se passa na superfície de nosso esferoide." (BAUDELAIRE, 2010 , p.24) Talvez possamos afirmar que o adulto, ao refletir sobre a paixão que sente pela sua própria singularidade, pela singularidade dos outros e pela diversidade do mundo, depara-se com a pergunta que, conforme Foucault, contribui para a recuperação da astúcia. Em outras palavras, o adulto que busca a experiência libertária do amor por si, pelos outros e pelo mundo, vê-se entregue à necessidade de constantemente refletir sobre a seguinte questão: "como não ser governado desta maneira, por aqueles, em nome destes princípios aqui, em vista de tais objetivos e por meio de tais procedimentos, não deste modo, não por isto, não por eles?"”

14 Na tradução do texto "Reflexões sobre a noção de "cultura de si'", no qual Hadot dialoga com a estética da existência de Foucault, há uma nota crítica que explica os motivos pelos quais se faz interessante traduzir o conceito hadotiano "dépassement de soi" por "ultrapassagem de si" e o conceito foucaultiano "franchissement possible" por "transgressão possível": "De modo geral, poderíamos afirmar que a transgressão possível se opõe à ultrapassagem de si, na medida em que consiste em um movimento imanente que não busca a dimensão utópica de um outro mundo, mas sim a transformação deste mundo e desta vida em algo novo, inusitado e, até então, impossível. O prefixo 'trans', diferentemente do prefixo 'ultra', expressaria o movimento imanente e heterotópico da vida daquele que pretende se relacionar criativamente com este mundo." (STEPHAN \& BOGANIKA in: HADOT, 2017, nota 41, p.201)

STEPHAN. Cassiana Lopes. Como não esquecer de viver o presente: um ensaio sobre a espiritualidade do amor. Griot : Revista de Filosofia, Amargosa - BA, v.18, n.2, p.375-396, dezembro, 2018. 
(FOUCAULT, 2015, p.37, tradução nossa) Por certo, a criação de relações afetuosas livres, nas quais a distinção do si e do outro podem ser exercidas de modo a manifestar e incidir na pluralidade do mundo, depende da reflexão em torno da referida questão. Entretanto, faz-se importante ressaltar que esta só se torna uma questão relevante à meditação do adulto quando ele desobedece às demandas do narcisismo, ou melhor, quando ele se entrelaça afetivamente com o outro cuja singularidade representa a revolta em relação ao destino que prescreve a fusão com a Beleza originária. Sob a clave da crítica como transgressão possível, a reflexão acerca da paixão pela singularidade de si e dos outros, bem como o ato libertário do amor, são mutuamente atrelados.

Conforme Baudelaire, as crianças perdem a astúcia referente à experiência do tempo presente na medida em que se habituam à regência da Natureza Universal, a qual é exercida pelos adultos que buscam se conformar a este ideal divino. Mais precisamente, como nos explica Bataille a propósito da atitude de criança que perpassa a literatura de Baudelaire, "a liberdade da criança (ou do diabo) é limitada pelo adulto (ou por Deus), que faz dela uma derrisão (que a minora)." (BATAILLE, 2015, p. 34) Isso significa que, para Baudelaire, viver o presente é ser capaz de perceber, através do esforço que visa rearticular o si mesmo ao poder da liberdade, o caráter fictício do Ideal, cuja função é fundamentar a realidade que minora a beleza da astúcia irrefletidamente vivenciada nos primórdios da infância. O adulto vive o presente quando critica aquelas autoridades que censuraram a sua astúcia e que, portanto, mitigaram a sua aptidão para a liberdade ao convencê-lo, como Fausto convenceu Helena, a abandonar-se ao destino amoroso que tem por finalidade identificá-lo à natureza do Todo. Nesse sentido, como mostra Bataille, para Baudelaire a criança que cresce precisa se esforçar reflexiva e ativamente em virtude da superação da altura dos pais, pois quando os defronta por cima de seus ombros, "ela pode ver que "por trás deles, não há nada'." (Idem., p.32)

A crítica nos permite vislumbrar que o Ideal não é nada de universal, necessário e obrigatório, ou seja, ela nos prepara para a aquisição da verdade relativa ao caráter fictício deste Ideal e da realidade que a ele se atrela. Baudelaire, ao afirmar que "o nada embeleza o existente" (BAUDELAIRE, 2010, p.69), parece nos mostrar, na via da estética da existência, que a beleza do real reside na sua singularidade, contingência e arbitrariedade, as quais constituem qualidades que manifestam tanto o aporte fictício disto que nos fez agir utopicamente em relação a nós mesmos, aos outros e ao mundo, quanto a possibilidade de criarmos a nossa "própria história, de fabricar como que por ficção a história [...]". (FOUCAULT, 2015, p.48, tradução nossa) Como afirma Foucault, perceber a dimensão fictícia do ideal no real consiste em "imaginá-lo diferentemente daquilo que ele é, a transformálo sem destruí-lo, mas captando-o naquilo que ele é. A modernidade baudelairiana é um exercício onde a extrema atenção ao real é confrontada à prática de uma liberdade que ao mesmo tempo respeita este real e o viola." (FOUCAULT, 2001, p.1389, tradução nossa) No caso de Baudelaire, a redução do ideal ao nada corresponde ao resgate crítico da astúcia capaz de nos conduzir ao presente: ao nos depararmos com a ficcionalidade daquilo que fundamentava as ações até então

STEPHAN. Cassiana Lopes. Como não esquecer de viver o presente: um ensaio sobre a espiritualidade do amor. Griot : Revista de Filosofia, Amargosa - BA, v.18, n.2, p.375-396, dezembro, 2018. 
entretidas por nós, retomamos a liberdade que transgressivamente nos desloca para fora daquela utopia atinente à longa tradição da espiritualidade do éros. Para o Baudelaire de Foucault, "a atitude voluntária de modernidade está ligada a um ascetismo indispensável." (Idem., tradução nossa) Sendo assim, faz-se possível afirmar que para Foucault o adulto é incapaz de vivenciar o presente quando se conforma ao conforto daquela ingênua obediência que o afasta deste mundo, seja pela fé no Ideal ou pela crença na segurança proporcionada pela privacidade de sua casa e de seu inconsciente. A vulnerabilidade do presente, no caso de Foucault, não se deve, como em Hadot, ao recalque da Razão universal como o elemento fundamental que une o si, o outro e o mundo, mas sim ao recalque do caráter fictício da realidade que constitui a nossa condição no mundo. De acordo com Foucault, para vivermos o presente precisaríamos modificar a nós mesmos sem recorrermos ao espelho de narciso, pois quando olhamos para este continuamos a enxergar o universal, o necessário e o obrigatório. Talvez tenhamos que recorrer a outro instrumento, isto é, a um instrumento que não faça da transfiguração ética do si e dos outros, bem como da intervenção política no mundo, uma utopia.

\section{Conclusão: o presente é vulnerável}

Estamos habituados a associar o presente ao espaço de tempo que nos permite conduzir o cotidiano, ou seja, ao espaço previamente dado que contempla a nossa trivialidade, iniciada no momento em que acordamos e rompida no instante em que as ações do inconsciente são liberadas pelo sono. Temos a impressão de que o presente não é vulnerável, temos a sensação de que ele é implacavelmente experenciado por nós. Contudo, quando decidimos nos voltar a esta sensação e pensar a respeito daquilo que ela representa, tornamo-nos capazes de perceber que tal impressão repousa sobre a inércia, a qual tem nos desviado da presença do presente e nos mantido presos à saudade, ao arrependimento e à ansiedade travestida de esperança benevolente por uma vida e um mundo melhores. Ao nos darmos conta destas sensações compreendemos, como disse Hadot, que esquecemos de viver o presente e que esta experiência, diferentemente do que imaginávamos, é vulnerável. P. Hadot e M. Foucault caracterizam a vulnerabilidade do presente quando nos mostram que ele não corresponde ao espaço de tempo sempre disponível aos sujeitos, mas que a experiência do presente depende da transfiguração ética do si mesmo e da sua intervenção política no mundo. No caso de Hadot, o movimento em direção ao presente possui uma dimensão utópica, já que o presente concerne ao efeito que se segue do ato amoroso capaz de conectar o si e o outro ao Divino. Nesse sentido, o presente desponta como o instante excepcional que oferece aos amantes a experiência da Beleza originária, a qual fundamenta e justifica tanto a condição da realidade que nos circunscreve quanto o nosso engajamento para com ela. Por outro lado, conforme Foucault, o presente corresponde ao efeito que resulta do desejo de amar a peculiaridade do si e do outro no mundo que, paradoxalmente, abarca continuidades e rupturas identitárias. Para Foucault, o movimento em direção ao presente possui um caráter ascético e um aporte fictício, pois o presente se apresenta aos amantes

STEPHAN. Cassiana Lopes. Como não esquecer de viver o presente: um ensaio sobre a espiritualidade do amor. Griot : Revista de Filosofia, Amargosa - BA, v.18, n.2, p.375-396, dezembro, 2018. 
como o instante no qual a beleza que os conecta, um ao outro e ambos ao mundo, é assim fabricada como que por ficção.

Por conseguinte, talvez possamos afirmar que a experiência do presente é vulnerável na medida em que depende do si mesmo. Como Hadot e Foucault nos explicam, a experiência do presente revela a faceta individual e social da vida justamente porque depende da maneira pela qual o si se movimenta em relação a si mesmo, aos outros e, portanto, ao mundo. Além disso, Hadot e Foucault nos mostram que a vulnerabilidade do presente também se deve aos outros, visto que a transformação ascensional ou ascética do si em algo outro depende da prática e da transfiguração social. Como vimos, Hadot estrutura a relação entre o si e os outros no narcisismo erótico de tradição platônica, enquanto Foucault nos propõe uma configuração ascética do amor, a qual aparentemente não se atrelaria aos reflexos do espelho de narciso. Foucault não parece se interessar pelo espelho que ensinara o si a reconhecer em si mesmo a Beleza originária, mas sim por aquilo que nos mostra que "temos um corpo, que este corpo tem uma forma, que esta forma tem um contorno, que no contorno há uma espessura, um peso." (FOUCAULT, 2013, p. 15) Foucault nos explica que desde a Antiguidade arcaica o espelho e o cadáver foram os responsáveis por nos ensinar "que o nosso corpo não é pura utopia." (Idem.) Por certo, o espelho ao qual Foucault se refere não é o mesmo utilizado por Hadot. Sendo assim, a nossa hipótese é a de que o espelho instrumentalizado por Foucault não nos remete ao reflexo de Narciso, mas sim à máscara de Medusa, a qual exibe àqueles que a encaram a precariedade da vida do corpo que fugazmente se torna cadáver. Como explica Vernant: "sobre a máscara de Medusa, como em um espelho de fundo duplo, sobrepõem-se e interferem-se a estranha beleza da face feminina, brilhante de sedução, e a fascinação horrível da morte." (VERNANT, 2011, p.129, tradução nossa)

Com efeito, a distinção entre Hadot e Foucault no que concerne à configuração dos vínculos amorosos, se utopicamente narcísicos ou ficcionalmente medúsicos, conduz-nos à interrogação sobre a maneira pela qual podemos compreender a relação entre a experiência do presente e a meditação da morte, tanto no que tange à tradição dos exercícios espirituais quanto no que se refere à cultura da estética da existência. Ademais, para finalizar, gostaríamos de indicar que a referida diferença também parece recair na distinção concernente ao modo pelo qual Hadot e Foucault concebem o aspecto sócio-político da vulnerabilidade do tempo presente, que ao mesmo tempo interfere e é interferido pelo aspecto estético-ético da transformação do si. Como podemos perceber, o enigma do tempo presente está longe de ser cabalmente resolvido, pois pensar e viver o presente depende, sobretudo, da agonia cujo paroxismo manifesta a faceta social e individual da vida no mundo enquanto nos coloca em questão, fazendo-nos transitar, como disse Foucault, entre a ascensão que nos "comunicará com as divindades" e a ascese que nos "comunicará com o universo do outro". (FOUCAULT, 2013, p.12) Estas duas formas de comunicação, ao invés de se excluírem, confrontam-se em diferentes níveis: da política à ética, da ética à estética, destas à psiché do sujeito que, simultaneamente, vive para a vida e para a morte de si mesmo, dos outros e do mundo. Diante disso,

STEPHAN. Cassiana Lopes. Como não esquecer de viver o presente: um ensaio sobre a espiritualidade do amor. Griot : Revista de Filosofia, Amargosa - BA, v.18, n.2, p.375-396, dezembro, 2018. 
interrompemos o nosso ensaio com a seguinte questão: conduzir a própria vida em direção ao presente é colocá-la face a face com a morte no mundo?

STEPHAN. Cassiana Lopes. Como não esquecer de viver o presente: um ensaio sobre a espiritualidade do amor. Griot : Revista de Filosofia, Amargosa - BA, v.18, n.2, p.375-396, dezembro, 2018. 


\section{Referências}

BATAILLE, G. A literatura e o mal. Tradução de Fernando Scheibe. Belo Horizonte: Autêntica, 2015.

BAUDELAIRE, C. O pintor da vida moderna. Tradução de Jérôme Dufilho e Tomaz Tadeu. Belo Horizonte: Autêntica, 2010.

BÉNATOUÏL, T. "Deux Usages du Stö̈cisme: Deleuze, Foucault". In: GROS, F.; LÉVY, C. Foucault et la Philosophie Antique. Paris: Éditions Kimé, 2003.

BRÉHIER, É. A teoria dos incorporais no estoicismo antigo. Tradução de Fernando Padrão de Figueiredo e José Eduardo Pimentel Filho. Belo Horizonte: Autêntica, 2012.

BRUNSCHWIG, J. "Metafísica estoica". In: INWOOD, B. Os estoicos. Tradução de Paulo Fernando Tadeu Ferreira e Raul Fiker. São Paulo: Odysseus, 2006.

BUTLER, J. Qu'est-ce qu'une vie bonne? Tradução de Martin Rueff. Paris: Payot \& Rivages, 2014.

EPICTETO. O Encheirídion de Epicteto. Edição bilíngue por Aldo Dinucci e Alfredo Julien, Sergipe: EdiUFS, 2012.

FOUGAULT, M. História da sexualidade 3: o cuidado de si. Tradução de Maria Thereza da Costa Albuquerque. Rio de Janeiro: Graal, 2011.

FOUGAULT, M. A hermenêutica do sujeito. Tradução de Márcio Alves da Fonseca e Salma Tannus Muchail. São Paulo: Martins Fontes, 2010.

FOUCAULT, M. Dits et écrits II. 1976-1988. Paris: Gallimard, 2001.

FOUCAULT, M. O corpo utópico; As heterotopias. Tradução de Salma Tannus Muchail. São Paulo: n-1, 2013.

FOUCAULT, M. Qu'est-ce que la critique suivi de La culture de soi. Paris: Vrin, 2015.

FREDE, D. "Determinismo estoico". In: INWOOD, B. Os estoicos. Tradução de Paulo Fernando Tadeu Ferreira e Raul Fiker. São Paulo: Odysseus, 2006.

GOETHE, J.W. Os sofrimentos do jovem Werther. Tradução de Marcelo Backes. Porto Alegre: L\&PM, 2011.

GOETHE, J.W. Fausto: uma tragédia - segunda parte. Tradução de Jenny Klabin Segall. São Paulo: Editora 34, 2011.

HADOT, P. Exercices spirituels et philosophie antique. Paris: Albin Michel, 1993.

HADOT, P. La philosophie comme manière de vivre: entretiens avec Jeannie Carlier et Arnold I. Davidson. Paris: Albin Michel, 2001.

HADOT, P. N'oublie pas de vivre: Goethe et la tradition des exercices spirituels. Paris: Albin Michel, 2008.

HADOT, P. "Reflexões sobre a noção de "cultura de si"”. In: Revista Filosófica de Coimbra. Tradução e notas de Cassiana Stephan e Luciane Boganika. Coimbra, vol.26, $\mathbf{n}^{\mathrm{o}}$ 51, março de 2017, pp.183-204.

HIEROCLES. Hierocles the Stoic: Elements of Ethics, Fragments and Excerpts. Edição bilíngue por David Kosntan e Ilaria Ramelli. Boston: Brill, 2009.

LONG, A.A; SEDLEY, D.N. The Hellenistic Philosophers: greek and latin texts with notes and bibliography. Cambridge: Cambridge University Press, 2003. 2v.

STEPHAN. Cassiana Lopes. Como não esquecer de viver o presente: um ensaio sobre a espiritualidade do amor. Griot : Revista de Filosofia, Amargosa - BA, v.18, n.2, p.375-396, dezembro, 2018. 
LORENZINI, D. La politique des conduites: pour une histoire du rapport entre subjectivation éthique et subjectivité politique. Tese Doutorado. Université Paris-Est Créteil, Créteil. 2014.

STEPHAN, C. Michel Foucault e Pierre Hadot: um diálogo contemporâneo sobre a concepção estoica do si mesmo. Dissertação de Mestrado. Universidade Federal do Paraná, Curitiba, 2015.

STIRNER, M. Textos Dispersos. Tradução de José Bragança de Miranda. Lisboa: Via Editora, 1979.

VERNANT, J-P. L'individu, la mort, l'amour. Paris: Galimmard, 2011.

Autor(a) para correspondência: Cassiana Lopes Stephan, Universidade Federal do Paraná, Faculdade de Filosofia, ciências e Letras, R. Gen. Carneiro, 460, Centro CEP 80060-150, Curitiba - PR, Brasil. cassianastephan@yahoo.com.br

STEPHAN. Cassiana Lopes. Como não esquecer de viver o presente: um ensaio sobre a espiritualidade do amor. Griot : Revista de Filosofia, Amargosa - BA, v.18, n.2, p.375-396, dezembro, 2018. 